\title{
Correction to: Impacts of WRF Model Domain Size on Meiyu Rainfall Forecasts over Zhejiang, China
}

\author{
Zhenshou $\mathrm{Yu}^{1,2}{ }^{(\mathbb{D}} \cdot$ Mengwen $\mathrm{Wu}^{1} \cdot$ Jinzhong $\mathrm{Min}^{3} \cdot \mathrm{Yu} \mathrm{Yan}^{4} \cdot$ Xiaofen $\mathrm{Lou}^{5}$
}

Published online: 9 November 2021

○ Korean Meteorological Society and Springer Nature B.V. 2021

\section{Correction to: Asia-Pacific Journal of Atmospheric Sciences https://doi.org/10.1007/s13143-021-00254-1}

Due to an unfortunate oversight a citation error has been found after online publication: "North Atlantic Oscillation (e.g., Liu et al. 2020a and b)" should read "North Atlantic Oscillation (e.g., Liu et al. 2020a)"

The original article has been corrected

Publisher's Note Springer Nature remains neutral with regard to jurisdictional claims in published maps and institutional affiliations.

The original article can be found online at https://doi.org/10.1007/ s13143-021-00254-1.

\section{Zhenshou Yu}

yuzhenshou@gmail.com

1 Zhejiang Institute of Meteorological Sciences, 139 Qianjiang Road, Hangzhou 310008, China

2 State Key Laboratory of Severe Weather, Chinese Academy of Meteorological Sciences, Beijing 100081, China

3 Key Laboratory of Meteorological Disaster of Ministry of Education (KLME) / Joint International Research Laboratory of Climate and Environment Change (ILCEC)

/ Collaborative Innovation Center on Forecast and Evaluation of Meteorological Disasters, Nanjing University of Information Science \& Technology, Nanjing 210044, China

4 Reading Academy, Nanjing University of Information Science \& Technology, Nanjing 210044, China

5 Zhejiang Meteorological Observatory, Hangzhou 310017 , China 